\title{
An evaluation of the current status of kidney transplant in terms of the type of receipt among Iranian patients
}

\author{
Arghavan Malekshahi ${ }^{1}$, Hamidreza Fallah MortezaNejad ${ }^{2}$, Morteza Rahbar Taromsari ${ }^{3}$, Reza Ghanei Gheshlagh ${ }^{4}$ \\ and Kourosh Delpasand ${ }^{5^{*}}$ (D)
}

\begin{abstract}
Introduction: With the increasing prevalence and incidence of chronic renal failure leading to advanced kidney disease (ESRD), the use of renal transplant therapy is increasing globally. The aim of this study was to determine the status of kidney transplant in patients during a period of $4-5$ years.

Materials and methods: In this retrospective, analytical study, patients undergoing renal transplant at one of the hospitals in northern Iran were studied. The data was collected using a checklist assessing the required information, including the age, sex, place of residence, source of the kidney for transplant (living related, living non-related, deceased), kidney receiving method (donated, purchased), and wait time for a kidney transplant.

Results: A total of 228 patients were included in the study, of which $73.7 \%$ were male and $26.3 \%$ were female. The average wait time for kidney transplant was 386.22 days. The mean age of patients was $32.7 \pm 10.7$ years. In addition, living non-related (66.2\%) and deceased (14\%) were the most and least frequent sources of kidney transplant, respectively. Moreover, $51.8 \%$ of all transplanted kidneys were purchased.

Conclusion: Over the past 5 years, there has been a decrease in wait time for kidney transplant in Rasht, Iran. Factors, such as being female, lower age, and living in urban areas, are related to a shorter wait time for kidney transplant. The most common types of kidney transplant are from non-related donors and purchased.
\end{abstract}

Keywords: Kidney transplant, Kidney failure, Medical ethics

\section{Introduction}

Kidney transplant is the transfer of a healthy kidney from a compatible donor to the body of another person with a disabled kidney [1] and is the most promising option for patients with end-stage renal disease [2]. At the first major conference on the ethical and legal questions of transplant in London in 1962, Dr. Joseph Murray, pioneer of kidney transplant, stated that the major problem in kidney transplant was related to supply and

\footnotetext{
* Correspondence: kouroshdelpasand@gmail.com

${ }^{5}$ Department of Medical Ethics, School of Medicine, Guilan University of Medical Sciences, Rasht, Iran

Full list of author information is available at the end of the article
}

demand [3]. The first organ transplant was conducted in Germany in 1954 from a living-related donor, and the first kidney transplant in the Middle East was performed in Shiraz, Iran, in 1967 [4-6]. The three main sources of kidney transplant include living related (related by consanguinity or affinity), unrelated with financial benefit or altruistic motivation, and brain-dead donors [1, 7]. Successful transplant eliminates the need for dialysis and leads to improved quality of life for the patient [1]. The shortage of kidney grafts from brain-dead donors and the increasing wait times for receiving kidney from this source have shifted the focus of the medical community toward living-donor kidney transplants. In 1986, for the 
first time in the Middle East, a living-donor kidney transplant was carried out in Iran [8], and in 1989, Ayatollah Khomeini, the leader of the Iranian Revolution, allowed living-donor kidney transplant, and this was the first religious authorization of its kind in the entire Shiite community [9]. In Western societies, living-donor kidney transplant is increasing [10]; for example, in France, more than 1400 living-donor kidney transplants were performed from 2000 to 2006 [2]. According to annual statistics, the highest number of living-donor kidney transplants are carried out in the USA (6435), Brazil (1768), Iran (1615), Mexico (1459), and Japan (939), respectively [11, 12]. Between 2006 and 2014, 3736 livingdonor kidney transplants were performed in Iran [11].

Live donors are related or non-related. Non-related donors may be altruistic donors or donate for money. In the past decades, the number of non-related altruistic donations has substantially increased in developed countries, but it is still much lower than the demand for kidney transplant, and this has led to serve shortage of kidney along with increased mortality rates and increased motivation for financial or truism kidney transplants [13].

Half of all transplants in developed countries, such as the US and the UK, come from live donors. Although the results of living-donor kidney transplant are more favorable than those of transplant from brain-dead donors, living donors are still at risk of death, complications from surgery, and potential long-term physical and psychological problems [14]. Living donors include related or unrelated donors. Non-family donors also donate either altruistically or for money.

According to the available statistics, most of kidney transplants performed in Iran so far have been from living donors [15]. In 1988, a living-unrelated donor kidney transplant program was adopted in Iran. As a result, the number of kidney transplant centers and kidney transplants increased rapidly, so that by 1999, the kidney transplant waiting list in the country was successfully eliminated. By the end of 2005, 19609 kidney transplants were performed in Iran. This approach was eventually named the Iranian model renal transplant program. Currently, $50 \%$ of ESRD patients in Iran live with a functional transplanted kidney [10]. The annual number of kidney transplants in Iran has gone from less than 100 transplants in 1986 to 1800 transplants in 2006 [16], and in recent years, the rate of kidney transplant has increased again, with approximately 2500-2700 kidney transplants performed per year [17].

Organ transplant is one of the important topics in the field of medical ethics. Due to the prevalence of organ transplant in Iran, this issue needs careful attention. Organ transplant was recognized in Iran as a result of scientific advances in this field, and as this topic became more widespread in Iran, religious scholars began to pay special attention to it and authorize it; while in some other countries, like Japan that is very advanced in terms of science and technology, there are still major cultural problems in terms of accepting this new phenomenon [18]. Also, given the importance of assessing the other aspects of living-donor kidney transplant, including ethical-legal issues, oversight, financial resources, donor's rights, conditions for selecting the donor, buying and selling organs, organ trafficking, we sought to investigate the status of kidney transplant in patients at one of the hospitals in northern Iran during a period of 5 years.

\section{Methods}

This is a retrospective, analytical study. The study population included Iranian patients undergoing kidney transplant between 2009 and 2018 at one of the hospitals in northern Iran; the hospital is allowed to perform kidney transplants. The statistical population was a limited population with about 600 members, given the number of kidney transplants performed over the past 10 years. Sample size was calculated using the Cochran formula. Based on an article by Tabatabai et al. [10], $P=$ 0.4 , and a significance level of $0.05,228$ patients were selected from the study population using a systematic random sampling method. The sampling process was as follows: One number was randomly selected among the medical record numbers, followed by selecting every two numbers until 228 patients were selected.

The data was collected using a checklist assessing the required information, including age, sex, place of residence, source of the kidney for transplant (living-related, living non-related, deceased), kidney receiving method (donated, purchased), and wait time for kidney transplant. First, the type of donor (living or deceased) was identified using the medical record; then, the patients were contacted by phone, and if they were willing to cooperate, the type of door and method of donation were identified. The inclusion criteria were as follows: consent to participate in the study and kidney transplant during the past 10 years; the exclusion criterion was incomplete medical records.

\section{Data analysis}

The data was analyzed by SPSS 21 software. Quantitative data was described using the mean and standard deviation, and qualitative data was analyzed using frequency percentage. Kidney transplant status tables were evaluated according to the underlying variables using chisquared test. Also, Poisson regression model was used to investigate the relationship between different variables and wait time for kidney transplant. The significance level was set at 0.05 . 


\section{Ethical consideration}

The ethics committee of Kurdistan University of Medical Sciences approved this study (no. IR.GUMS.REC.1398.058). Consent was obtained from every patient who was contacted by phone (after explaining the process of data collection and the importance of this process in assessing the status of kidney transplant). In addition, the participants were reassured that their personal information was kept confidential. Moreover, the real names of the participants were not used in reporting the data.

\section{Results}

The mean age of participants at the time of admission was $32.7 \pm 10.7$ years. The mean age of the study population was $28 \pm 7.5$. years for males and $45.7 \pm 7$ years for females. As shown in Table 1, 228 kidney transplants were evaluated, of which 168 (73.7\%) were male and 60 (26.3\%) female. The most and least frequent donor types were non-related (151 cases, 66.2\%) and deceased (32 cases, $14 \%$ ), respectively. In addition, $51.8 \%$ of the received kidneys were purchased and $48.2 \%$ were donated altruistically. Moreover, 152 patients (66.7) lived in urban areas.

Table 2 presents the findings of the Poisson regression model to examine the relationship between different variables and wait time for kidney transplant. As shown in the table, the coefficient of variation for age is 9.2, which is statistically significant. This indicates that the chance of getting a kidney transplant increases with age. Also, the coefficient of variation for being female is 430.8 and is statistically significant. This shows that the wait time for kidney transplant is significantly shorter for women than for men. In addition, the wait time for kidney transplant is 178.9 days shorter when the donor is nonrelated than when the kidney is received from other types of donors; the difference is statistically significant. If the donor is related, the wait time for transplant is 38.1 days shorter, and the different is statistically significant. Also, if the kidney is purchased, the wait time for

Table 1 Descriptive statistics

\begin{tabular}{|c|c|c|c|c|c|c|c|}
\hline \multirow[t]{3}{*}{ Variables } & \multirow[t]{3}{*}{ Sex } & \multicolumn{2}{|c|}{ Male } & \multicolumn{2}{|c|}{ Female } & \multicolumn{2}{|c|}{ Total } \\
\hline & & $n$ & $\%$ & $n$ & $\%$ & $n$ & $\%$ \\
\hline & & 168 & 73.7 & 60 & 26.3 & 228 & 100 \\
\hline \multirow[t]{3}{*}{ Type of donor } & Deceased & 32 & 14 & 0 & 0 & 32 & 14 \\
\hline & Related & 45 & 19.7 & 0 & 0 & 45 & 19.8 \\
\hline & Non-related & 91 & 39.9 & 60 & 26.3 & 151 & 66.2 \\
\hline \multirow[t]{2}{*}{ Type of kidney } & Purchased & 94 & 41.2 & 24 & 10.5 & 118 & 51.8 \\
\hline & Donated & 74 & 32.5 & 36 & 15.8 & 110 & 48.2 \\
\hline \multirow[t]{2}{*}{ Residency } & Urban areas & 118 & 51.8 & 34 & 14.9 & 152 & 66.7 \\
\hline & Rural areas & 50 & 21.9 & 26 & 11.4 & 76 & 33.3 \\
\hline
\end{tabular}

Table 2 The relationship between different variables and wait time for kidney transplant

\begin{tabular}{|c|c|c|c|c|}
\hline Variable & Wait time & Coefficient & Standard error & $P$ value \\
\hline$\overline{\text { Age }}$ & 296.4 & 9.2 & 1.45 & $>0.0001$ \\
\hline \multicolumn{5}{|l|}{ Sex } \\
\hline Male & 364.2 & - & 1.5 & $>0.0001$ \\
\hline Female & 106.5 & -430.8 & 33.6 & \\
\hline \multicolumn{5}{|l|}{ Type of Donor } \\
\hline Deceased & 437.5 & - & - & $>0.0001$ \\
\hline Related & 271.3 & -178.9 & -4.8 & \\
\hline Non-related & 280 & -381.1 & -9.3 & \\
\hline \multicolumn{5}{|l|}{ Type of kidney } \\
\hline Purchased & 340.8 & - & - & $>0.0001$ \\
\hline Donated & 248.7 & -170.3 & 6 & \\
\hline \multicolumn{5}{|l|}{ Residency } \\
\hline Urban areas & 285.3 & - & - & $>0.0001$ \\
\hline Rural areas & 318.6 & -130.2 & -7.5 & \\
\hline
\end{tabular}

kidney transplant is 170.3 days shorter; the difference is significant. In addition, there is a significant relationship between place of residence (urban or rural areas) and wait time for kidney transplant. The coefficient of variation for residence in rural areas was 130.22 which was statistically significant. This indicates that people who lived in rural areas waited longer for kidney transplant than those living in urban areas.

\section{Discussion}

Kidney transplant is the treatment of choice for endstage renal patients; in other words, it improves both survival and quality of life of patients and is more costeffective compared to dialysis $[19,20]$. The purpose of this study was to evaluate the status of kidney transplant in patients at Razi Hospital in Rasht between 2009 and 2010. The mean age of participants was 32 years; this indicates that the mean age of kidney transplant patients in our study was lower compared to the similar studies $[21,22]$. These days, age is considered an important risk factor for mortality. The sex distribution showed that more than two thirds of the participants were male; this is a relatively large proportion. One of the most important reasons for the relationship between age and gender with the incidence of kidney problems is that men are more exposed to the predisposing factors. In fact, men are more vulnerable to the risk factors for kidney problems and tend to care less about their own health due to having a busy life.

In this study, about $71 \%$ and $19 \%$ of transplanted kidneys were from non-related and related donors, respectively. From the scientific point of view, living-related donor kidney transplant is more desirable than a 
deceased unrelated donor kidney transplant, especially when the donor is among first-generation relatives [8]. People with higher socioeconomic status are more likely to get kidney transplant [23]. It is somewhat difficult for donors to believe that they can continue to live as a normal person after donating their kidney, and patients are often unwilling to receive kidney from their close relatives. At the same time, unrelated kidney donation is largely motivated by economic reasons, except in altruistic cases. People with low socioeconomic status may decide to sell their kidneys to cope with financial problems. In order to prevent kidney trafficking, laws and regulations passed in 2009 in the Philippines state that donors should have an emotional or social relationship with recipients.

About $14 \%$ of the preformed transplants were from deceased donors, indicating that there has been no progress in cadaveric kidney transplantation, despite the brain death kidney donation law in Iran; and despite the presence of kidney transplant technology in Iran, most kidney transplants were purchased. On the other hand, studies have shown that despite the greater chance of human anti-leukocyte mismatch (HLA) in living-donor kidney transplant than deceased-donor kidney transplant, the former has better outcomes [8, 24]. This factor may partly explain why deceased-donor kidney transplants are less popular than living-donor kidney transplants. In addition, due to cultural and religious factors, Asian countries are still at the beginning of this process [25]. The first deceased-donor kidney transplant in Iran was performed 16 years after the first living-donor kidney transplant and the problem of sex selection still affects deceased-donor kidney transplants. However, in the last few years, the number of deceased-donor kidney transplants has increased in comparison to the number of related or unrelated living-donor kidney transplants $[8,14]$. The findings also showed that wait time for kidney transplant was significantly longer in rural areas than in urban areas, which could be due to lower socioeconomic status or less access to educational centers in rural areas. This can be attributed to a lack of awareness; therefore, it is suggested that access to health facilities should be facilitated in rural areas.

Wait time for kidney transplant also varies in other countries; for example, between January 1, 2004, and June 30, 2009, patients in Alabama had an average wait time of more than 72 months, while their counterparts in Oregon waited 19 months [26, 27]. In our study, the wait time for kidney transplant was about 1 year, indicating that access to kidney donors is facilitated at this health center.

Wait time was also significantly correlated with age and sex, so that it was shorter for younger people; this implies that more attention is paid to younger patients.
Also, women have significantly shorter wait times than men; this finding can be explained by the fact that significant attention is paid to the health needs of women in Iranian families. Regarding age, it can be said that younger people are more likely to have related-donor kidney transplants. In addition, men and the elderly tend to pay less attention to kidney problems, while women are more sensitive to them, and tend to seek treatment for their kidney problems earlier than men.

There was also a significant association between wait time and type of donor, with people receiving kidney from related donors waiting shorter for kidney transplant than those receiving kidney from unrelated or deceased donors, and those receiving kidney from deceased donors waiting significantly longer on the waiting list than the other two groups. In addition, those receiving a purchased kidney had waited shorter on the waiting list than those receiving a donated kidney.

\section{Conclusion}

The study results show that over the past 10 years, wait time for kidney transplant has decreased in Rasht compared to other cities in Iran. In addition, factors, such as being female, younger age, and living in urban areas, were related to a shorter wait time for kidney transplant; this may be due to the fact that people in these groups are more likely to seek kidney transplant. Moreover, most received kidneys were purchased and from unrelated donors; this can be due to financial issues related to buying and selling kidney in Iran and the unpopularity of receiving kidney from diseased or related donors due to cultural aspects of the Iranian population. Despite the fact that many roads in cities in northern Iran are accident-prone, and that there is a high rate of brain death in this province, brain dead donor kidneys are rarely used in kidney transplants; this is an issue that warrants special attention. Therefore, it is important to encourage people to get organ donation cards and encourage families of brain dead patients to participate in organ donation.

\section{Authors' contributions}

AM: data collection; KD and HFM: study design; RGG and MRT: final revision and grammar editing; RGG and KD: statistical analysis. The authors read and approved the final manuscript.

\section{Funding \\ None}

Availability of data and materials

The datasets used and/or analyzed during the current study are available from the corresponding author on reasonable request.

Ethics approval and consent to participate

Not applicable

Consent for publication

Not applicable 


\section{Competing interests}

The authors declare that they have no competing interests.

\section{Author details}

'Social Determinants of Health Research Center, Guilan University of Medical Sciences, Rasht, Iran. ${ }^{2}$ Medical Ethics and Law Research center, Shahid Beheshti University of Medical Sciences, Tehran, Iran. ${ }^{3}$ Department of Forensic Medicine, School of Medicine, Razi Hospital, Guilan University of Medical Sciences, Rasht, Iran. ${ }^{4}$ Spiritual Health Research Center, Research Institute for Health Development, Kurdistan University of Medical Sciences, Sanandaj, Iran. ${ }^{5}$ Department of Medical Ethics, School of Medicine, Guilan University of Medical Sciences, Rasht, Iran.

Received: 2 September 2020 Accepted: 30 November 2020

Published online: 14 December 2020

\section{References}

1. Mahdavi MM, Heidary Rouchi A, Norozi S, Aghighi M, Rajolani H, Ahrabi S. Renal Replacement therapy in Iran. Urol J. 2007;4(2):66-70.

2. Sun FF, Wang $Y, X u$ WZ, Tian $Y$, Zhang L, Tang YW, et al. Medical ethical management: support for living related-donor kidney transplant. Transplant Proc. 2011;40(10):458-61 https://doi.org/10.1002/dat.20595.

3. Harris J. In praise of unprincipled ethics. J Med Ethics. 2003;29:303-6 https:// doi.org/10.1136/jme.29.5.303

4. Masri M, Haberal M. Solid-organ transplant activity in MESOT countries. Exp Clin Transplant. 2013;11(2):93-8 https://doi.org/10.6002/ect.2013.ecte3.

5. Larijani B. Organ transplant (medical, ethical, legal, and religious aspects) (Persian Language). Tehran: Entesharat Baraye Farda; 2005. p. 1.

6. Ghods AJ, Savaj S. Iranian model of paid and regulated living unrelated kidney donation. Clin J Am Soc Nephrol. 2006;1(6):1136-45 https://doi.org/ 10.2215/CJN.00700206

7. Schena F. Epidemiology of end stage renal disease: international comparisons of renal replacement therapy. Kidney Int. 2000;57:39-45 https://doi.org/10.1046/j.1523-1755.2000.07407.x.

8. Simforoosh N, Basiri A, Tabibi A, Nadjafi-Semnani M. Living unrelated kidney transplant: does it prevent deceased-donor kidney transplant growth? Exp Clin Transplant. 2019;17:250-3 https://doi.org/10.6002/ect.MESOT2018.P110.

9. Mahdavi-Mazdeh M, Rouch AH. Renal transplant, the Iranian model. In: García-García G, Agodoa LY, Norris KC, editors. Chronic kidney disease in disadvantaged populations. 1st ed. London: Academic; 2017. p. 303-12. https://doi.org/10.1016/B978-0-12-804311-0.00028-5.

10. Tabatabahi A, Hashemi S, Kabiri M, Yazdani M, Taheri S, Hosen Pourm M, et al. Evaluation of kidney transplant results from living donor, non-relative and cadaver donors in Isfahan. J Isfahan Med Sch. 2005;24(82):26-9.

11. Daar AS, Khitamy A. Bioethics for clinicians: 21. Islamic bioethics. CMAJ. 2001;164(1):60-3.

12. Lazar \& Hemic, Webster, Dickens. 2001. pp. 33-6. 6.

13. Ghodsm A, Ossareh S, Savaj S. Results of renal transplant of the Hashemi Nejad Kidney Hospital-Tehran. In: Cecka JM, Terasaki PI, editors. Clinical Transplants 2000. Los Angeles: UCLA Tissue Typing Laboratory; 2001. p. 203-10

14. Hariharan S, Johnson CP, Bresnahan BA, Taranto SE, Mclntosh MJ, Stablein D. Improved graft survival after renal transplant in the United States, 1988 to 1996. N Engl J Med. 2000;342(9):605-12 https://doi.org/10.1056/ NEJM200003023420901.

15. Cacho DT, Cusí LI, Piqué AA, Villar PB, Reyes LI, Alvarez-Vijande García R, et al. Elderly donor kidney transplant: factors involved in graft survival. Transplant Proc. 2005;37(9):3690-2 https://doi.org/10.1016/j.transproceed. 2005.09.130.

16. Shrestha BM, Haylor JL. Factors influencing long-term outcomes following renal transplant: a review. JNMA J Nepal Med Assoc. 2007;46(167):136-42 https://doi.org/10.31729/jnma.290.

17. Meier-Kriesche HUPF, Ojo AO, Rudich SM, Hanson JA, Cibrik DM, et al. Effect of waiting time on renal transplant outcome. Kidney Int. 2000;58(3):1311-7 https://doi.org/10.1046/j.1523-1755.2000.00287.x

18. Timmerman L, Laging M, Westerhof GJ, Timman R, Zuidema WC, Beck DK, et al. Mental health among living kidney donors: a prospective comparison with matched controls from the general population. Am J Transplant. 2015; 15(2):508-17 https://doi.org/10.1111/ajt.13046.

19. Omar F, Tinghog G, Carlsson P, Omnell-Persson M, Welin S. Priority setting in kidney transplant: a qualitative study evaluating Swedish practices. Scand
J Public Health. 2013;41(2):206-15 https://doi.org/10.1177/ 1403494812470399.

20. Danovitch GM. Handbook of kidney transplant. Philadelphia: Lippincott Williams \& Wilkins; 2009

21. Farahani ZB, Esmaeili M, Salsali M, Nayeri ND. Living related transplant: the outcomes of kidney donation in Iran. Acta Med Mediterr. 2016;32:1071-6.

22. Suzanne C, Smeltzer O. Brunner \& Suddarth's textbook of medical surgical nursing. 12th ed. Philadelphia: Wolters Kluwer/Lippincott Williams \& Wilkins; 2010. p. 642-51.

23. Ardekani MS, Orlowski JM. Multiple listing in kidney transplant. Am J Kidney Dis. 2010;55(4):717-25 https://doi.org/10.1053/j.ajkd.2009.11.022

24. Simforoosh N, Soltani MH, Basiri A, Tabibi A, Gooran S, Sharifi SHH, et al. Evolution of laparoscopic live donor nephrectomy: a single-center experience with 1510 cases over 14 years. J Endourol. 2014;28(1):34-9.

25. Alatab S, Pourmand G. Implication of thymoglobulin in kidney transplant patients: review article. Tehran Univ Med J. 2015;73(8):545-53 [In Persian].

26. Time to transplant [Table 7]. Available at: http://www.srtr.org/csr/ archives/ 201006/ORUOOP1XX201006.pdf. Accessed 30 Aug 2014.

27. Time to transplant [Table 7]. Available at: http://www.srtr.org/csr/ archives/ 201012/ALOBOP1XX201012.pdf. Accessed 30 Aug 2014.

\section{Publisher's Note}

Springer Nature remains neutral with regard to jurisdictional claims in published maps and institutional affiliations.
Ready to submit your research? Choose BMC and benefit from:

- fast, convenient online submission

- thorough peer review by experienced researchers in your field

- rapid publication on acceptance

- support for research data, including large and complex data types

- gold Open Access which fosters wider collaboration and increased citations

- maximum visibility for your research: over $100 \mathrm{M}$ website views per year

At BMC, research is always in progress.

Learn more biomedcentral.com/submission 